\title{
Cytotoxic Effects of Betel Vine, Piper betle Linn. Leaf Extracts Using Artemia salina Leach (Brine Shrimp Lethality Assay)
}

\author{
Magdalene Mae L. Del Socorro, Clifford P. Bendoy, \\ Charity May L. Dacayana
}

Natural Sciences Department, College of Arts and Sciences, Misamis University, Ozamiz City, Philippines

Corresponding author: Magdalene Mae L. Del Socorro, email: maedelsocorro@gmail.com

\begin{abstract}
Evaluation of cytotoxic effects of plants is as essential as their phytochemical appraisal in medicinal botany and drug discovery. In this study, the cytotoxic activity of the methanol, ethanol, and crude aqueous extracts of the plant Betel Vine Piper betle Linn. under the family Piperaceae was evaluated using the brine shrimp lethality (BSL) assay. Cytotoxic activity of $P$. betle was assessed based on lethality concentration. Brine shrimp eggs were hatched, and 10 resulting nauplii were added to the diluted test solutions at varying concentrations - $5 \mu \mathrm{g} / \mathrm{mL}, \quad 50 \mu \mathrm{g} / \mathrm{mL}$, and $500 \mu \mathrm{g} / \mathrm{mL}$. Surviving Artemia salina Leach shrimp nauplii were counted after 24 hours and lethality concentration was determined. Maximum mortality of the brine shrimp was observed at the highest treated-concentration whereas least mortality at the lowest treated-concentration. Ethanol and methanol crude extracts showed significant cytotoxic activity with $\mathrm{LC}_{50}$ values of $23.65 \mu \mathrm{g} / \mathrm{mL}$ and $85.50 \mu \mathrm{g} / \mathrm{mL}$, respectively, which indicated the presence of potent cytotoxic components of the plant. Hence, $P$. betle is found to be containing cytotoxic compounds but this result does not necessarily suggest complete toxicity of the plant because it may also suggest potential antitumor or anticancer activities.
\end{abstract}

Keywords: antitumor, Betel, cytotoxicity, lethality, nauplii 


\section{Introduction}

Plants are the main source of raw materials for plantbased medicines since time immemorial (Vasuki et al., 2011). Plant-based natural constituents can be derived from the leaves, fruits, flowers, seeds, roots, stems and bark or any part of the plant that may contain an active component. Valuable medicinal property of plant materials results from the combinations of secondary products present in the plant (Islam et al., 2010). Plants reported having medicinal properties may play two roles in the development of new drug, as a phytomedicine to be used for the treatment of diseases (Iwu, 2014) or as a natural blueprint for the development of new drugs. Nowadays, studies on plants for their medicinal property are significantly increasing, substantiated by a large number of scientific researches done on certain plants that are said to be of medicinal use. However, merely a small fraction has been suitably studied in terms of their phytochemical constituents and pharmacological properties (Alagammal et al., 2013; Rates, 2001).

Medicinal plants used today benefit broad acceptance through the population and serve as cheaper alternatives to traditional medicine (Baravalia et al., 2012). However, many plants are identified to be toxic. The scientific concern has now been diverted towards the natural components which are biocompatible, safe and also cost-effective. Thus, studies are continuously being conducted to identify further and validate the scientific authenticity of such agents. For this reason, the study is conducted in order to determine the toxicity of the plant.

Piper betle Linn. commonly known as the betel vine is one of the notably studied plants displaying potential medicinal property. Piper plants are considered an ecologically and economically important species in the Family Piperaceae consisting of about 1,000-2,000 species. Betel vine is a perennial, dioecious, semiwoody climber which has leaves that have a strong pungent flavor generally used as masticatory (Hewageegana et al., 2011; Datta et al., 2011). It is a stout twining climber with broadly ovate-oblong or ovate cordate leaves, tiny yellow-green flowers and small spherical fruits (Islam et al., 2010; Periyanayagam et al., 2012). It is commonly grown in the tropical humid climate of Southeast Asia used both as a recreational and medicinal plant (Chaurasia et al., 2010). 
In the Philippines, early Filipinos used $P$. betle as offering to guests who visited their homes. In those times according to Valdes (2004), offering a tray of "buyo" or "hitso", the native term of betel chew, was the essence of urbanity which was an act of courtesy and politeness in every house especially in the homes of the wealthy. Failure of a homeowner to offer betel to anyone who entered his house would be a serious breach of hospitality. Hence, during that time offering of betel was an essential component of every rite of passage such as birth, courtship, bethrothal and marriage, healing and death.

Leaves of $P$. betle are commonly consumed as a post-meal mouth freshener that is beneficial to the throat. Leaves are also used to improve digestion and to treat venereal sores, dysentery, syphilis, phthisis and intestinal strangulation. In India, the leaves are also used as antiseptic (Datta et al., 2011), to prevent excessive bleeding during menstruation (Biswas et al., 2011), carminative and expectorant (Rajeshbabu et al., 2011). Juice of leaves is used as eye drops in painful ophthalmic affections and to treat night blindness (Patel et al., 2012), fever, cough, and fatigue (Rai et al., 2011). It has been reported to display biological properties of antioxidation, detoxication, and antimutation that suggest its potential chemopreventive property against a variety of ailments including liver fibrosis (Fathilah et al., 2010). Extracts of this plant are also shown to have effects on human spermatozoa, antiaphrodisiac activity, antinociceptive and wound healing properties (Hewageegana et al., 2011). However, betel leaves display detrimental effects as described in the Ayurvedic texts for they have been observed to deaden the taste buds of the tongue, weaken the teeth and impair health.

Notwithstanding the efficacy of medicinal herbs such as the $P$. betle for the treatment of a range of diseases, insufficiency on the standard prescriptions on dosage and the crude use of the preparations impede the use of these plants in medicine. These may possibly cause complications consequential from over utilization and possible consumption of toxic plant ingredients as well as the probability of plant to plant or plant to drug interactions. 
Thus, due to the wide medicinal application and reported potential medicinal properties of the plant, this study intended to determine the potential cytotoxic effects of $P$. betle leaf extracts using Brine Shrimp Lethality Assay to further investigate its potential medicinal properties and evaluate possible adverse effects it may cause.

As noted by Meyer et al. (1982), brine shrimp lethality assay was considered as a suitable probe for preliminary evaluation of toxicity, detection of fungal toxins, pesticides, heavy metals and cytotoxicity assessment of dental materials. Brine shrimp is commonly used as the test organism in a range of bioassay systems substantiated by reports on the utilization of this animal for environmental studies, screening for natural toxins and general screening for bioactive compounds in plant extracts (Montanher et al., 2002).

Artemia salina Leach (Brine shrimp) is an invertebrate inhabiting saline aquatic and marine ecosystem. According to Ramachandran et al. (2011), it can be used in a laboratory bioassay in order to determine toxicity of plants by the estimation of the medium lethality concentration $\mathrm{LC}_{50}$ which has been reported for a series of toxins and plant extracts.

Several research findings reveal the huge potential of betel leaves for therapeutic treatment, despite the fact that they have not been completely investigated. Therefore, there is a need for more studies to be conducted for the thorough investigation of the plant.

\section{Materials and Methods}

\section{Preparation of leaf extracts}

Leaves of Piper betle Linn. were collected, cleaned with water, dried in the shade and were pulverized into fine powdered substance by a grinding machine. Air-dried ground plant sample was extracted with each of the solvents - ethanol, methanol and water.

About 60 grams of the osterized plant samples were percolated with $250 \mathrm{~mL}$ of $95 \%$ ethanol for three days and then filtered with Whatmann No. 1 filter paper. Filtrate was concentrated in vacuo using a rotary evaporator and subsequently subjected to liquid nitrogen to obtain dry sample. Dried samples were stored in small sterile glass containers. 
Approximately, 60 grams of $P$. betle powder were weighed and soaked in $500 \mathrm{~mL} 95 \%$ methanol for 24 hours. Subsequently, crude extracts were filtered by passing them through Whatmann No. 1 filter paper and were concentrated under vacuum using a rotary evaporator. Residual extracts were then stored in the refrigerator at $4{ }^{\circ} \mathrm{C}$ in small and sterile plastic bottles.

Aqueous extraction procedure was done by boiling cleaned fresh leaves in enough distilled water. Decoction was allowed to cool, and then filtered using filter paper (Whatmann No.1), stored in a cleaned glass container and then subjected to freeze-drying for three days.

\section{Cytotoxicity test}

Brine shrimp lethality assay was performed according to the simplified method of Meyer et al. (1982) with minor modifications to investigate the cytotoxicity of $P$. betle crude methanolic, crude ethanolic, and crude aqueous leaf extracts. Brine shrimps (Artemia salina Leach) were hatched using brine shrimp eggs in a glass tank with two unequalsized compartments filled with boiled filtered seawater. One compartment of the tank was covered with aluminum foil and fully aerated. The airstone was carefully placed at the bottom of the tank to ensure sufficient aeration of the eggs. The brine shrimp eggs were then incubated for approximately 24 hours at room temperature and were illuminated. Subsequently, hatched active nauplii were attracted to the other side of the tank with a light source and were collected using a Pasteur pipette then consequently used for the assay.

Test solutions were prepared by initially dissolving separately $20 \mathrm{mg}$ of methanol, ethanol, and aqueous residual extracts of $P$. betle in $2 \mathrm{~mL}$ dimethyl sulfoxide (DMSO) to increase the solubility of the extract and further diluted with boiled filtered seawater to produce the required concentrations. Appropriate amounts of the test solutions at 5-, 50-, or $500-\mu \mathrm{L}$ for 10,100 , and $1000 \mu \mathrm{g} / \mathrm{mL}$, were transferred to separate vials, respectively. Ten active nauplii were drawn and transferred to each sample vial, added with previously boiled filtered seawater to make a final volume of $5 \mathrm{~mL}$. Tests were done in triplicates. Control tests containing 5-, 50- or 500- $\mu \mathrm{L}$ DMSO in $5 \mathrm{~mL}$ boiled, filtered seawater with ten active nauplii were also prepared in triplicates for each concentration. The set-up was allowed to stand for approximately 24 hours under constant illumination 
after which the survivors were counted. Percentage mortality at each test solution was determined using the following formula:

$\%$ mortality $=($ no. of dead nauplii / initial no. of live nauplii) $\mathrm{X} 100$

Graphical method of Probit analysis was used to calculate $\mathrm{LC}_{50}$, the concentration at which lethality to brine shrimps represents $50 \%$ (Finney, 1971). Extracts with $\mathrm{LC}_{50}$ values $<100 \mu \mathrm{g} / \mathrm{mL}$ were considered significant (Gupta, 1996).

\section{Results and Discussion}

Cytotoxic activity of methanolic, ethanolic and crude aqueous leaf extracts of $P$. betle determined using brine shrimp lethality assay is shown in Table 1. Results obtained from the BSL assay showed maximum mortalities at $500 \mu \mathrm{g} / \mathrm{mL}$, the highest treated-concentration, while least mortalities were observed at $5 \mu \mathrm{g} / \mathrm{mL}$ which is the lowest treatedconcentration.

Table 1. Toxicity of Piper betle Linn. leaf extracts on the brine shrimp Artemia salina Leach.

\begin{tabular}{lccccc}
\hline \hline $\begin{array}{c}\text { Leaf } \\
\text { Extracts }\end{array}$ & $\begin{array}{c}\text { Concentration } \\
(\boldsymbol{\mu g} / \mathbf{m L})\end{array}$ & $\begin{array}{c}\text { No. of } \\
\text { Survivors, 24hrs }\end{array}$ & $\begin{array}{c}\text { No. of } \\
\text { Deaths, 24hrs }\end{array}$ & $\begin{array}{c}\text { Percentage } \\
\text { Mortality }(\mathbf{\%})\end{array}$ & $\begin{array}{c}\mathbf{L C}_{\mathbf{5 0}} \\
(\boldsymbol{\mu} \mathbf{g} / \mathbf{m L})\end{array}$ \\
\hline \multirow{3}{*}{ Crude } & 5 & 25 & 5 & 16.6 & \\
methanolic & 50 & 17 & 13 & 43.3 & 85.50 \\
& 500 & 0 & 30 & 100 & \\
Crude & 5 & 23 & 7 & 23.3 & \\
ethanolic & 50 & 14 & 16 & 53.3 & 23.65 \\
& 500 & 0 & 30 & 100 & \\
Crude & 5 & 20 & 10 & 33.3 & 1035 \\
aqueous & 50 & 18 & 12 & 40.0 & \\
\hline \hline
\end{tabular}

It is evident that the observed percentage mortalities are directly proportional to the concentration of $P$. betle crude leaf extracts; the number of deaths increased as concentration increased. In the evaluation of the three leaf extracts for cytotoxicity using A. salina, it can be depicted that degree of lethality is directly proportional to the concentration of the extract. Ethanol and methanol crude extracts exhibited cytotoxic activity 
with $\mathrm{LC}_{50}$ values of $23.65 \mu \mathrm{g} / \mathrm{mL}$ and $85.50 \mu \mathrm{g} / \mathrm{mL}$, respectively. In addition, aqueous crude extract of $P$. betle from decoction showed cytotoxic activity with $\mathrm{LC}_{50}$ value of $1035 \mu \mathrm{g} / \mathrm{mL}$. The $\mathrm{LC}_{50}$ values found for ethanol and methanol crude extracts indicated significant cytotoxic activity against $A$. salina. The $\mathrm{LC}_{50}$ value $<100 \mu \mathrm{g} / \mathrm{ml}$ is considered significant. In the in vitro cytotoxicity study by Chaurasia et al. (2010), $P$. betle aqueous extract was observed to have cytotoxic effects on the HEp-2 cell line by MTT and SRB assays.

In another study conducted by Roy and Vijayalaxmi (2013), a significant increased death rate of cancer cell lines was generally observed with an increase in the concentration of the $P$. betle extract and the time of the incubation with the extract. This result indicates that the extract exhibited a dose-dependent and time-dependent activity against the cancer cells. These cytotoxic or antitumor properties may be due to the phytochemicals present in the plant such as polyphenols and alkaloids, most of which are potent free radical scavengers. Polyphenols are known to exhibit antitumor activities in various types of cancer (Roy \& Vijayalaxmi, 2013). In the study of Khan and Kumar (2011), $P$. betle ethanolic and methanolic extracts were shown to have antimicrobial property against pathogenic bacteria namely Escherichia coli, Pseudomonas aeruginosa and Staphylococcus aureus which is attributed to the compounds present in the plant such as flavonoids and tannins that may have inhibited their growth. Flavonoids have been shown to inhibit the development of cancer while exhibiting antioxidant activities (Roy \& Vijayalaxmi, 2013). In one study by Abrahim et al. (2012), ethyl acetate $P$. betle extracts showed antiproliferative effect against breast cancer cell line, MCF-7 which indicates its great potential as a source of natural antioxidants.

Among the three $P$. betle extracts, the crude ethanol and methanol extracts showed more cytotoxic activity against the A. salina nauplii. Cytotoxic activity results of extracts in this study are attributed to the amount of cytotoxic compounds extracted by each solvent. As noted by Sultana et al. (2009), vigor of the extraction procedure primarily affects the components that can be extracted from the plant material which may probably vary from sample to sample. The efficiency of the extraction solvent to dissolve endogenous substance might also be another very important contributing factor (Sultana et al., 2007). 
The significant lethality of $P$. betle extract towards brine shrimp is an indication of the presence of potent cytotoxic components in the plant. However, according to Elumba et al. (2013), cytotoxicity of a certain compound or natural product does not always suggest its outright toxicity but may also suggest its potential antitumor or anticancer activity. The observed potential antitumor or anticancer activity of $P$. betle is consistent with the findings of the studies of Pradhan et al. (2013) which showed the antimutagenic property of the plant, and Rai et al. (2011) which revealed its anticarcinogenic properties against the tobacco carcinogens due to the presence of phytoconstituents like hydroxychavicol and chlorogenic acid. The latter compound is reported to kill cancer cells without affecting the normal cells unlike the common anticancer drugs (Rai et al., 2011). Thus, the cytotoxic activity exhibited by $P$. betle in this endeavor supports the use of the plant in customary medicine as well as the reported studies on the cytotoxic, antitumor or anticancer and antiproliferative activities of the plant.

\section{Conclusion and Recommendation}

The brine shrimp lethality assay of $P$. betle leaf extracts showed a significant $\mathrm{LC}_{50}$ values of $<100 \mu \mathrm{g} / \mathrm{mL}$ towards $A$. salina which indicates the presence of potent cytotoxic components in the plant. Thus, Piper betle Linn. is found to be containing cytotoxic compounds but this does not necessarily suggest complete toxicity because it may also suggest potential antitumor or anticancer activities. Further detailed isolation and identification of the bioactive compounds present in the plant should be done to prove its potential medicinal use.

\section{Acknowledgment}

The authors acknowledge the support of the Misamis University Research Center. The researchers would also like to express their special thanks to the Department of Chemistry at Mindanao State University-Iligan Institute of Technology for allowing the use of their equipment during the conduct of the study. 


\section{Literature Cited}

Abrahim, N. N., Kanthimathi, M. S., \& Abdul-Aziz, A. (2012). Piper betle shows antioxidant activities, inhibits MCF-7 cell proliferation and increases activities of catalase and superoxide dismutase. $B M C$ Complementary and Alternative Medicine, 12(1), 220. doi:10.1186 /1472-6882-12-220

Alagammal, M., Paulpriya, K., \& Mohan, V. R. (2013). Anticancer activity of ethanol extract of Polygala javana DC whole plant against Dalton ascites lymphoma. Research Journal of Recent Sciences, 2(2), 18-22.

Baravalia, Y., Vaghasiya, Y., \& Chanda, S. (2012). Brine Shrimp cytotoxicity, anti-inflammatory and analgesic properties of Woodfordia fruticosa Kurz Flowers. Iranian Journal of Pharmaceutical Research, 11(3), 851-861.

Biswas, K. R., Khan, T., Monalisa, M. N., Swarna, A., Ishika, T., Rahman, M., \& Rahmatullah, M. (2011). Medicinal plants used by folk medicinal practitioners of four adjoining villages of Narail and Jessore districts, Bangladesh. American-Eurasian Journal of Sustainable Agriculture, 5(1), 23-33.

Chaurasia, S., Kulkarni, G. T., \& Shetty, L. N. (2010). Phytochemical studies and in vitro cytotoxicity screening of Piper betle leaf (PBL) extract. Middle-East Journal of Scientific Research, 6(5), 532-536.

Datta, A., Ghoshdastidar, S., \& Singh, M. (2011). Antimicrobial property of Piper betel leaf against clinical isolates of bacteria. International Journal of Pharmaceutical Sciences and Research, 2(3), 104-109. 
Elumba, Z. S., Teves, F. G., \& Madamba, M. R. S. B. (2013). DNAbinding and cytotoxic activities of supercritical- $\mathrm{CO}_{2}$ extracts of Ganoderma lucidum (Curt.:Fr.) P. Karst. collected from the wild of Bukidnon Province, Philippines. International Research Journal of Biological Sciences, 2(3), 62-68.

Fathilah, A. R., Sujata, R., Norhanom, A. W., \& Adenan, M. I. (2010). Antiproliferative activity of aqueous extract of Piper betle L. and Psidium guajava L. on $\mathrm{KB}$ and HeLa cell lines. Journal of Medicinal Plants Research,4(11), 987-990. doi: 10.5897/ JMPR09.093

Finney, D. J. (1971). Probit Analysis (2nd ed.). New York, NY: Cambridge University Press.

Gupta, M. P., Monge, A., Karikas, G. A., Lopez de Cerain, A., Solis, P. N., De Leon, E., ...\& Sanchez, C. (1996). Screening of Panamanian medicinal plants for brine shrimp toxicity, crown gall tumor inhibition, cytotoxicity and DNA intercalation. Pharmaceutical Biology, 34(1), 19-27.

Hewageegana, H. G. S. P., Arawwawala, L. D. A. M., Arambewela, L. S. R., \& Ariyawansa, H. S. (2011). Piper betle Linn: As a remedy for diabetes mellitus. International Journal of Research in Ayurveda \& Pharmacy, 2(5), 1601-1603.

Islam, K. M., Howlader, M. A., Kundu, G. C., Bulbul, I. J., \& Ahsan, M. R. (2010). Free radical scavenging activity of chloroform and ethyl acetate extracts of leaves of Piper betle Linn. Libyan Agriculture Research Center Journal International, 1(6), 384-387.

Iwu, M. M. (2014). Handbook of African medicinal plants (2nd ed.). Boca Raton, FL: CRC Press Taylor \& Francis Group.

Khan, J. A., \& Kumar, N. (2011). Evaluation of antibacterial properties of extracts of Piper betel leaf. Journal of Pharmaceutical and Biomedical Sciences, 11(11), 1-3. 
Meyer, B. N., Ferrigni, N. R., Putnam, J. E., Jacobsen, L. B., Nichols, D. E., \& McLaughlin, J. L. (1982). Brine shrimp: A convenient general bioassay for active plant constituents. Planta Medica, 45(5), 31-34. doi: $10.1055 / \mathrm{s}-2007-971236$

Montanher, A. B. P., Pizzolatti, M. G., \& Brighente, I. M. C. (2002). An application of the brine shrimp bioassay for general screening of Brazilian medicinal plants. Acta Farmaceutica Bonaerense, 21(3), 175-178.

Patel, G., Patil, U. K., \& Uma Devi, P. (2012). Preliminary study on the effect of Piper betle on the growth of transplanted B16F10 melanoma in mice. International Journal of Recent Advances in Pharmaceutical Research, 2(1), 67-71.

Periyanayagam, K., Jagadeesan, M., Kavimani, S., \& Vetriselvan, T. (2012). Pharmacognostical and phyto-physicochemical profile of the leaves of Piper betle L. var Pachaikodi (Piperaceae) - Valuable assessment of its quality. Asian Pacific Journal of Tropical Biomedicine, 2(2), S506-S510. doi:10.1016/S22211691(12)60262-7

Pradhan, D., Suri, K. A., Pradhan, D. K., \& Biswasroy, P. (2013). Golden heart of the nature: Piper betle L. Journal of Pharmacognosy and Phytochemistry, 1(6), 147-167.

Rai, M. P., Thilakchand, K. R., Palatty, P. L., Rao, P., Rao, S., Bhat, H. P., \& Baliga, M. S. (2011). Piper betel Linn (betel vine), the maligned Southeast Asian medicinal plant possesses cancer preventive effects: Time to reconsider the wronged opinion. Asian Pacific Journal of Cancer Prevention, 12(9), 2149-56.

Rajeshbabu, P., Ayyanar, M., Rasool, S. K., Sheriff, M. A., \& Sekar, T. (2011). In vitro antibacterial activity of Piper betle L. and black betel CV. Kammar leaves against Staphylococcus aureus and Streptococcus pneumoniae. Journal of Pharmacy Research, 4(7), 2223-2225. 
Ramachandran, S., Vamsikrishna M., Gowthami, K. V., Heera, B., \& Dhanaraju, M. D. (2011). Assessment of cytotoxic activity of Agave catula using brine shrimp (Artemia salina) lethality bioassay. Asian Journal of Scientific Research, 4(1), 90-94. doi: 10.3923/ajsr.2011.90.94

Rates, S. M. K. (2001). Plants as source of drugs. Toxicon, 39(5), 603-613. doi:10.1016/S0041-0101(00)00154-9

Roy, U. B., \& Vijayalaxmi, K. K. (2013). Evaluation of cytotoxic activity of Piper betle Linn. using murine and human cell lines in vitro. International Journal of Scientific \& Engineering Research, 4 (9), 221-233.

Sultana, B., Anwar, F., \& Ashraf, M. (2009). Effect of extraction solvent/technique on the antioxidant activity of selected medicinal plant extracts. Molecules, 14(6), 2167-2180. doi:10.3390/ molecules 14062167

Sultana, B., Anwar, F., \& Przybylski, R. (2007). Antioxidant activity of phenolic components present in barks of Azadirachta indica, Terminalia arjuna, Acacia nilotica, and Eugenia jambolana Lam. trees. Food Chemistry, 104(3), 1106-1114. doi: 10.1016/ j.foodchem.2007.01.019

Valdes, C. O. (2004). Betel chewing in the Philippines. Arts of Asia, 34(5), 104-115.

Vasuki, K., Senthamarai, R., Kirubha, T. S. V., Balasubramanian, P., \& Selvadurai, S. (2011). Pharmacognostical studies on leaf of Piper betle. Der Pharmacia Lettre, 3(5), 232-235. 